REGULAR ARTICLE

\title{
DATA ENVELOPMENT ANALYSIS AS A TOOL FOR EVALUATION OF EMPLOYEES' PERFORMANCE
}

\author{
Peter Zbranek
}

Address: Slovak University of Agriculture, Faculty of Economics and Management, Department of Statistics and Operations Research, Tr. A. Hlinku 2, 94976 Nitra, Slovak Republic

Corresponding author: xzbranek@is.uniag.sk

\begin{abstract}
Employee performance evaluation systems, which are well designed and properly used, are essential for the effective functioning of the organization. Due to some disadvantages of traditional methods, there is a need to develop new evaluation procedures. The main contribution of this paper is to apply a multidimensional approach, represented by the method of Data Envelopment Analysis (DEA) to measure the performance and efficiency of employees. This approach overcomes several weaknesses of traditional systems of the employees' performance evaluation and provides a comprehensive indicator of the performance of individual employees, their technical efficiency score. The input variables of the used model were the motivational factors (salary, working conditions and benefits); the output was the indirectly assessed performance through work motivation, job satisfaction and organizational commitment. Furthermore, we applied the nonparametric methods for compliance testing of mean values to validate the stated hypotheses. In a baking company using the DEA method, we identified 12 efficient employees and 48 employees who need to improve their outputs to achieve their maximum efficiency.
\end{abstract}

Keywords: motivational factors, work motivation, job satisfaction, organizational commitment, employees` performance, Data Envelopment Analysis

JEL classifications: C44 


\section{INTRODUCTION}

One of the key conditions for achieving a high performance of organization is the high performance of its own employees. Therefore, great efforts were spent in order to develop most objective and effective system by which would be their performance evaluated. Company management would respond, on the basis of obtained results, either by the remuneration or promotion for good performance or by encouraging employees to achieve performance improvements.

Evaluation of employee performance (Performance Appraisal - PA) was defined by Pearce and Porter (1986) as a structured, formal interaction between a subordinate and supervisor, which provides the basis for the identification and elimination of differences in performance among employees. Nowadays, we know several traditional rating systems. They are performed by one or more supervisors, members of the work team, colleagues, or the selfassessment. In general, they are focused on the detection of three criteria - results, behaviour and personality characteristics (Manoharan, Muralidharan and Deshmukh, 2009). The most common method of evaluating employees in enterprises is a performance-oriented approach. The company pre-sets standards and their fulfilment is subsequently checked (Ilavský, 2008). Manoharan, Muralidharan and Deshmukh (2009) provide in their work an overview of other frequently used systems, such as an essay appraisal, critical incident appraisal, checklist, graphic rating scale, forced choice, behaviourally anchored rating scale, group order ranking, individual ranking, paired comparison, management by objectives and 360-degree feedback.

Several authors pointed out numerous shortcomings and disadvantages of the traditional system of employee performance evaluation. Therefore, there is a need for new systems to improve the evaluation process. Many efforts are spent on the development of new software tools that can serve as an advisor to managers.

Data Envelopment Analysis (DEA) is a nonparametric approach to evaluate efficiency, using linear programming tools. It is a method that combines several inputs and outputs of decision-making units into a single comprehensive indicator, the level of technical efficiency of each DMU. The main goal of this method is to identify efficient decision-making units that produce the largest quantity of outputs using the least amount of inputs (Lotfi and Shirouyehzad, 2010).

The DEA is currently one of the most common methods of operations research. It is often used in evaluation of a relative performance of the set of companies that use the same 
inputs for the production of the same outputs, for example branches of banks, farms, hospitals, shops and the like. Even individual employees of the organization might be evaluated units. Motivational factors that management of company uses to influence their performance may be regarded as inputs and job performance of employees may be considered as an output.

Compared to the traditional system of performance evaluation, this method has several advantages. It provides a comprehensive index, allowing an objective evaluation and comparison of employees, taking into account not only the outputs but also the inputs, plus it can handle multiple inputs and outputs simultaneously. Furthermore, DEA responds to employees' expectations about quantifying their shortcomings, overcoming the disadvantages of quality evaluation systems and is not dependent on the units of measurement. Since this is a non-parametric approach, DEA is not bound by the normal distribution of input and output variables (Manoharan, Muralidharan and Deshmukh, 2009).

On the other hand, there are also some disadvantages of the method. Results are sensitive to the selection of inputs and outputs, so their relative importance needs to be analyzed prior to the calculation. However, there is no way to test their appropriateness. The number of efficient decision making units (DMU) on the frontier tends to increase with the number of inputs and output variables (Berg, 2010).

Despite the mentioned advantages there are very few studies in the literature that addressed application of DEA method for evaluating employees' performance. Research in this area is mainly done in the field of sport to rate players with a single efficiency score. The method was applied in baseball (Anderson and Sharp, 1997; Kim and Cho, 2004; Sueyoshi, Ohnishi and Kinase, 1999; Mazur, 2004), basketball (Cooper, Ruiz and Sirvent, 2009; Bai and Lam, 2009), football (Hiroshu, Akiyama and Ueda, 2011; Kim and Bao, 2006) or tennis (Ruiz and Pastor, 2011).

Interesting paper, which partially influenced this text, was published by scientists from Tehran University, Lotfi and Shirouyehzad (2010), who evaluated the performance of 55 employees of a company involved in the distribution industry. They used four motivating factors as inputs - wages, working conditions, responsibility and amount of work. Performance was evaluated through outputs which have the largest impact - work motivation, job satisfaction, commitments to the organization and employee turnover. Further papers, in which the authors applied the method of DEA to evaluate performance of employees, were published by Manoharan, Muralidharan and Deshmukh (2009) and Osman (2010). 
The main purpose of this paper is to verify the possibility of using efficiency evaluation methodology Data Envelopment Analysis to measure employees' performance. A secondary purpose of this work is to examine the impact of demographic factors on the calculated technical efficiency score of employees, using various statistical techniques.

The rest of this article is organized as follows: section 2 describes the method of Data Envelopment Analysis, specifically its output-oriented model, and also description of outputs and inputs of used model. Results of research conducted in the bakery business can be found in section 3 and in section 4 we summarize some important findings and recommendations for further development in this area.

\section{MATERIAL AND METHODS}

Let us have n mutually compared decision making units (DMU) producing outputs $y_{r j}(r=1$, $2, \ldots, s)$, using inputs $x_{i j}(i=1,2, \ldots, m)$. If we use output-oriented model DEA with constant returns to scale for evaluation of decision making unit $\mathrm{DMU}_{0}$, then we are solving the following linear programming task.

Objective function:

$\varphi_{0}^{*}=\max \varphi_{0}$

Subject to:

$$
\begin{array}{ll}
\sum_{j=1}^{n} x_{i j \lambda_{j}} \leq x_{i 0} & i=1,2, \ldots, m \\
-\varphi y_{r 0}+\sum_{j=1}^{n} y_{r j} \lambda_{j} \geq 0 & r=1,2, \ldots, n \\
\lambda_{j} \geq 0 & j=1,2, \ldots, n
\end{array}
$$

where:

$x_{i j}$ is $\mathrm{i}$ input of $\mathrm{j}$ employee;

$y_{r j}$ is $\mathrm{r}$ output of $\mathrm{j}$ employee;

$x_{i o}$ is i input of evaluated employee;

$y_{r o}$ is $\mathrm{r}$ output of evaluated employee;

$\lambda_{j}$ is intensity variable of $\mathrm{j}$ employee;

$\varphi_{o}$ is the coefficient of expansion of output, the technical efficiency score of the evaluated employee. 
The result of thus formulated linear programming task is technical efficiency score $\varphi_{o}$ of evaluated decision making unit, in this case, the employee, which is defined as the ability to achieve maximum outputs at a given level of inputs. This measurement indicates how many times level of outputs has to be proportionally increased, maintaining the unchanged level of inputs, for employee to be technically efficient. If $\varphi_{o}$ equals one and a variable $\lambda_{j}$ is equal one for rated employee and zero for all other employees, the employee is technically efficient. Otherwise, if the technical efficiency measurement $\varphi_{o}$ is greater than 1 , the employee is not technically efficient in comparison with others and must increase outputs while level of inputs remains the same. If employee is rated inefficient, non-zero variables $\lambda_{j}$ points to the elements of referential set. Convex combination of outputs and inputs of efficient employees' reference set with coefficients $\lambda_{j}$ indicates so called target values, i.e. values of inputs and outputs of a virtual efficient reference employee on the frontier. Model assumes constant returns to scale, which means the proportional change in outputs due to the change of inputs. Therefore, if the inputs increase by $1 \%$, outputs also increase by $1 \%$.

We used three input and three output variables in our work. Inputs were salary (average salary range stated in employees' questionnaire), working conditions consisting of machinery, safety at work, the temperature at the workplace, work organization and working time (ordinary scale of 1 - really poor and 10 - definitely suitable) and benefits (employee can identify benefits that the employer provides). Selected company does not evaluate employees' performance. Therefore, as an output we have chosen three things that, according to several published studies, have a positive effect on it - work motivation, job satisfaction and commitment to the organization. Their level was determined by the attitudes of employees to 25 questions in the questionnaire on a 6-level Likert-type scale from strongly disagree to strongly agree. The first 15 propositions ascertained the level of working motivation of employees. On the basis of the responses we calculated so called Motivating Potential Score (MPS) of individual respondents presented in the work of Hackman and Oldham (1976). 5 additional statements were taken from the job satisfaction research by Brayfield and Rothe (1951) and the last 5 ascertained commitments to the organization, according to research of Mowday, Steers and Porter (1979). A representation of the model can be seen in table 1 .

Table 1 Inputs and outputs of the model

\begin{tabular}{ll}
\hline \hline Inputs & Outputs \\
\hline \hline Salary & Work motivation \\
Working conditions & Job satisfaction \\
Benefits & Organizational commitment \\
\hline \hline
\end{tabular}


In the last step we used the non-parametric tests of compliance of mean values to test validity of the hypotheses on the impact of demographic factors (age, gender, length of service, level of education, employment status and number of previous jobs) on the technical efficiency score of employees. We exploited following methods: Kruskal-Wallis test and Wilcoxon-Mann-Whitney two sample test.

\section{RESULTS AND DISCUSSION}

DEA method for employee performance evaluation was implemented in bakery business, which employs 120 workers. Information was collected through questionnaires. Return rate of questionnaires was $50 \%$.

In the first part we investigated demographic characteristics of respondents. We examined age, gender, employment status, highest level of education, length of service and number of previous jobs. The resulting statistics are presented in table 2:

Table 2 Demographic characteristics

\begin{tabular}{|c|c|c|c|}
\hline Variable & $\%$ & Variable & $\%$ \\
\hline \multicolumn{2}{|c|}{ Gender } & \multicolumn{2}{|c|}{ Employment status } \\
\hline male & 53 & administrative & 33 \\
\hline female & 47 & operating department & 67 \\
\hline \multicolumn{2}{|c|}{ Age } & \multicolumn{2}{|c|}{ Length of service } \\
\hline $18-25$ & 6 & $0-1$ year & 5 \\
\hline $26-35$ & 37 & $1-5$ years & 38 \\
\hline $36-45$ & 30 & $5-10$ years & 30 \\
\hline $46-55$ & 25 & more than 10 years & 27 \\
\hline more than 55 & 2 & Number o & \\
\hline \multicolumn{2}{|c|}{ The highest level of education } & none & 7 \\
\hline primary school & 2 & $1-2$ & 63 \\
\hline secondary school & 88 & $3-5$ & 23 \\
\hline university & 10 & more than 5 & 7 \\
\hline
\end{tabular}

We calculated the technical efficiency scores of individual employees when we applied described Data Envelopment Analysis model (1). Results indicated 12 efficient employees whose technical efficiency score was equal to 1 and 48 employees with score greater than 1 . These workers need to improve their performance to achieve full efficiency. Average technical efficiency score was 1.24 , meaning that the average employee of a company had almost $81 \%$ of the best employee's performance. Worst employee had technical efficiency score of 2.06, which was only $49 \%$ of the employees with the maximum efficiency. Descriptive statistics for the level of technical efficiency can be seen in table 3 . 
We further explored the impact of demographic factors on the technical efficiency score of employees through statistical procedures mentioned in the methodology. Test results are presented in table 4.

Table 3 The technical efficiency score, descriptive statistics

\begin{tabular}{lllllll}
\hline \hline Variable & Mean & St.Dev. & Minimum & Maximum & Mode & Median \\
\hline \hline$\varphi$ & 1,244 & 0,253 & 1 & 2,062 & 1 & 1,189 \\
\hline \hline
\end{tabular}

Table 4 Results of statistical tests

\begin{tabular}{lll}
\hline \hline Factor & Test & P-value \\
\hline \hline Age & Kruskal-Wallis Test & 0,116 \\
Gender & Wilcoxon Two-Sample Test & 0,109 \\
Level of education & Kruskal-Wallis Test & 0,579 \\
Employment status & Wilcoxon Two-Sample Test & 0,906 \\
Length of service & Kruskal-Wallis Test & 0,022 \\
Number of previous jobs & Kruskal-Wallis Test & 0,861 \\
\hline \hline
\end{tabular}

Notes: If the P-value is less than or equal to a significance level (alpha $=0,05$ ), the impact of a given factor is statistically significant. If the $P$-value is greater than 0,05, the impact of a given factor is not statistically significant.

Time that employee spent in the company had a statistically significant impact on his efficiency measure. The longer employee worked in the company, the better his performance (efficiency score) was. Employees have built a relationship with organization over the years; they are more committed, willing to make greater effort than is expected of them. After 10 years of working, however, there has been deterioration in performance, which may be connected with reduced motivation to work after long years spent in the same company. The company should therefore try to motivate such employees, whether with new work tasks or greater independence. Results are presented in table 5.

Table 5 The impact of the length of service on employees efficiency score

\begin{tabular}{lllllll}
\hline \hline Length of service & Mean & St.Dev. & Min & Max & Mode & Median \\
\hline \hline 0-1 year & 1,44 & 0,019 & 1,426 & 1,462 & & 1,431 \\
1-5 years & 1,218 & 0,159 & 1 & 1,572 & 1 & 1,207 \\
5-10 years & 1,142 & 0,206 & 1 & 1,63 & 1 & 1,045 \\
more than 10 years & 1,359 & 0,364 & 1 & 2,062 & 1 & 1,24 \\
\hline \hline
\end{tabular}

The impact of other demographic characteristics was not statistically significant. The efficiency score has worsened in average with increasing age, men were on average slightly more efficient than women. Educated workers were slightly more efficient than employees with lower level of educational attainment. An interesting finding was that while the 
administrative employees were more motivated, happier and more committed than their colleagues in operating department, technical efficiency did not differ significantly between these groups of employees. This is due to the fact that the level of motivational factors offered to administrative employees was higher. So, from the overall perspective, both groups were equally efficient. There was no significant difference among workers with different numbers of previous employment.

\section{CONCLUSION}

The aim of this paper was to apply the method of Data Envelopment Analysis in assessing employee performance. After applying classical output-oriented CCR DEA model in the baking business we rated 12 employees as fully efficient (out of total 60 employees). For the remaining 48 we recommended to take measures to improve their performance, such as education and training plan and evaluate them again over some time with the same variables and calculate so called Malmquist index. If even then there is no improvement, it is necessary to think about other measures.

Furthermore, we discovered that the length of service has statistically positive impact on employee performance. This increases their commitment to the organization and they are willing to do more. The performance of the employees who work for the company for more than 10 years, however, is worsening probably due to reduced work motivation. That is why the management of the organization should motivate them more.

Because of distinct advantages of DEA method over traditional systems of employee performance evaluation we recommend to apply it in the future, particularly in companies whose management has exact data on inputs and outputs of individual employees. We recommend using IDEA method, working with imprecise data; only in companies with more employees (number of employees should be at least 30 times higher than the total number of input and output variables).

\section{REFERENCES}

ANDERSON, T.R. - SHARP, G.P. 1997. A New Measure of Baseball Batters Using DEA. In Annals of Operations Research, vol. 73, 1997, 141-155.

BAI, F. - LAM, K.F. 2009. Testing the effects of environmental variables on efficiency and generating multiple weight sets for cross-evaluation with DEA: An application to the 
National Basketball Association: M.Phil. thesis. Kowloon, Hong Kong: City University of Hong Kong, Department of Management Science, 2009.

BERG, S. 2010. Water Utility Benchmarking: Measurement, Methodology, and Performance Incentives. London, UK: IWA Publishing, 2010. 172 p. ISBN: 9781843392729.

BRAYFIELD, A.H. - ROTHE, H.F. 1951. An Index of Job Satisfaction. In Journal of Applied Psychology, vol. 35, 1951, 307-311.

COOPER, W.W. - RUIZ, J.L. - SIRVENT, I. 2009. Selecting Non-zero Weights to Evaluate Effectiveness of Basketball Players with DEA. In European Journal of Operational Research, vol. 195, 2009, 563-574.

HACKMAN, J.R. - OLDHAM, G.R. 1976. Motivation through the Design of Work: Test of a Theory. In Organizational Behavior and Human Performance, vol. 16, 1976, 250-279.

HIROTSU, N. - AKIYAMA, D. - UEDA, T. 2006. Evaluation of J-League Players Using DEA. Juntendo University, School of Health and Sport Science, Inzai City, 2006.

ILAVSKÝ, M. 2008. Ako hodnotit' výkony l’udí. In Trend [online]. 2008. Available: $<\mathrm{http}: / /$ www.etrend.sk/trend-archiv/rok-/cislo-November/ako-hodnotit-vykonyludi.html>

KIM, T. - BAO, J. 2006. A DEA Based Performance Measurement and Management of Sports Players Using English Premier League Data. Soul National University, Soul, Korea, 2006.

KIM, T. - CHO, H. 2004. Performance Evaluation and Management of Baseball Players. In Review of Business and Economics, vol. 17, 2004, 2331-2348.

LOTFI, F.H. - SHIROUYEHZAD, H. 2010. Analyzing Efficiency of Human Resource Performance Using Data Envelopment Analysis. 1.st Conference on executive MBA, 2010, 12.

MANOHARAN, T.R. - MURALIDHARAN, C. - DESHMUKH, S.G. 2009. Employee Performance Appraisal Using Data Envelopment Analysis: A case study. In Research and Practice in Human Resource Management, vol. 17, 2009, 92-101.

MAZUR, M.J. 1994. Evaluating the Relative Efficiency of Baseball Players. In Charnes A. et al.: Data Envelopment Analysis: Theory, methodology and application, Boston: Kluwer Academic Publisher, 369-391.

MOWDAY, R.T. - STEERS, R.M. - PORTER, L.W. 1979. The Measurement of Organizational Commitment. In Journal of Applied Psychology, vol. 74, 1979, 224-250. 
OSMAN, I.H. 2010. Data Envelopment Analysis Model for the Appraisal and Relative Performance Evaluation of Nurses at an Intensive Care Unit. Springer Science \& Business Media.

PEARCE, J.L. - PORTER, L.W. 1986. Employee Responses to Formal Performance Appraisal Feedback. In Journal of Applied Psychology, vol. 71, 1986, 211-218.

RAMANATHAN, R., 2003. An Introduction to Data Envelopment Analysis: A Tool for Performance Measurement. New Delhi: Sage Publications India Private Ltd., 2003..

RUIZ, J.L. - PASTOR, J.T. 2011. Assessing Professional Tennis Players Using Data Envelopment Analysis (DEA). In Journal of Sports Economics, 2011.

SUEYOSHI, T. - OHNISHI, K. - KINASE, Y. 1999. A Benchmark Approach for Baseball Evaluation. In European Journal of Operational Research, vol. 115, 1999, 429-448. 